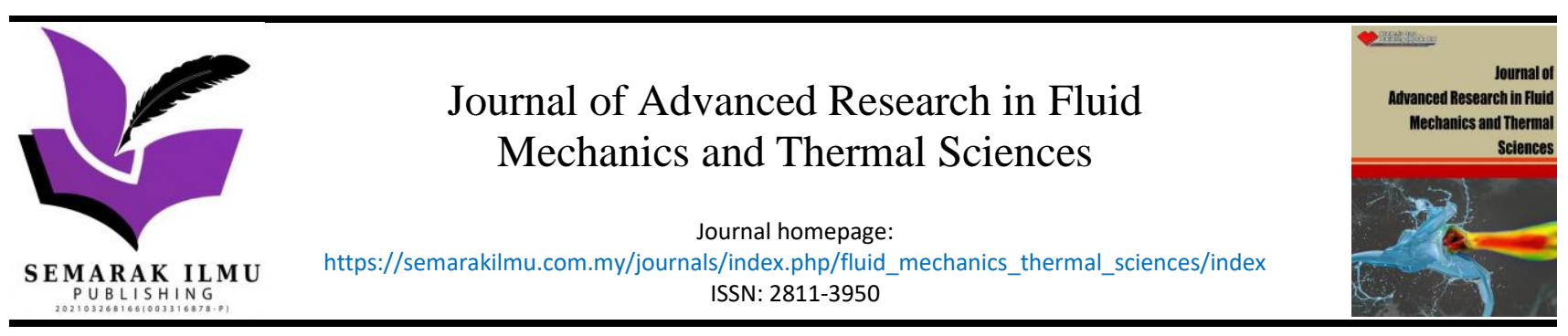

\title{
Assessment and Prediction of Heat Transfer Performance of Oscillating Heat Pipe using Acetone
}

\author{
M. Prashanth ${ }^{1}$, D. Madhu², K. Ramanarasimha ${ }^{3}$, R. Suresh ${ }^{4, *}$ \\ Department of Mechanical Engineering, Government Engineering College, Hassan-573201, Karnataka, India \\ Department of Mechanical Engineering, Government Engineering College, Ramanagar-562159, Karnataka, India \\ Department of Mechanical Engineering, K.S School of Engineering and management, Banaglore-560109, Karnataka, India \\ Department of Mechanical and Manufacturing Engineering, M.S. Ramaiah University of Applied Sciences, Bangalore-560058, Karnataka, India
}

\section{ARTICLE INFO}

\section{Article history:}

Received 28 October 2021

Received in revised form 15 December 2021

Accepted 20 December 2021

Available online 21 January 2022

\section{Keywords:}

Oscillating Heat Pipe (OHP); Acetone; Heat Performance; Fill Ratio; Thermal Resistance; Heat Transfer Coefficient

\section{ABSTRACT}

Heat pipe is a device to enhance the performance of heat transfer, in particular to transition phase change process. The present investigation is carried out to measure the thermal performance of a closed loop acetone filled oscillating heat pipe with four turns is fabricated and tested. The test was carried out for the inner diameter of 1.7 $\mathrm{mm}$ copper tube by varying the acetone of $50 \%, 60 \%, 70 \%$ and $80 \%$ filler ratio with a heat input of $15 \mathrm{~W}$ to $40 \mathrm{~W}$ in steps of $5 \mathrm{~W}$ has been considered. The results shows that $80 \%$ acetone filled OHP provides the better thermal performance with an average minimum temperature difference between condenser and evaporator by $6.03 \%$, heat transfer coefficient increased by $77 \%$ and the thermal resistance decrease by $43 \%$ respectively. The mathematical modelling was developed to predict the performance of the heat transfer. The model clearly shows that the independent variables are statistically significant with a p-value of 0.05 and the uncertainty analysis between the experimental and predicted values are less than $10 \%$.

\section{Introduction}

In heat pipes, pulsating heat pipe was the promising device for the heat transportation in heat transfer unit. Therefore, micro-grooved OHP is one of the effective modes to evaluate the performance heat transfer of the system. This device would enhance the allowable input heat flux by condensate the backflow to the evaporator when the filling ratio ranging from $30 \%$ to $60 \%$ [1]. Due to increase in filling ratio, heat added to the evaporator section leads to increase in temperature and pressure during the flow process. Therefore, filler ratio was the major part to increase the heat input for the oscillation motion of the working fluid [2]. To heat the oscillating pipe many methods was applied in the evaporator section. There was a pulsed supply with regulated current method was used to heat the system. This method generates a large amplitude oscillation to heat up for a short period of time [3]. To increase the heat transfer mechanisms of oscillating pipe a mathematical model

\footnotetext{
* Corresponding author.

E-mail address: sureshchiru09@gmail.com
}

https://doi.org/10.37934/arfmts.91.1.140154 
was developed by considering spring mass system to for an annular flow with a slug causing of penetrate liquid. This flow trains the liquid by disappearing the vapour bubbles by creating the pulsating effect of the liquid [4]. For the performance improvement of oscillating pipe mixing of selfrewetting fluids and nano-fluids was developed. To determine the high performance of the OHP optimum concentration of the nanoparticles (16\%) and self-rewetting (12\%) was used [5]. In case of hybrid flexile oscillating heat pipe at the adiabatic section at the heating and cooling side, a micro grooved copper tube was designed and fabricated. This structural design creates a deformation of adiabatic section and exhibits a spatial flexibility to improve the heat transfer performance of the new design [6]. If the filler ratio was $40 \%$ to $80 \%$ in case of self-rewetting fluid can ensure a higher heating load compare to water or ethanol as a working medium with a filler ratio of $30 \%$ [7]. Multilayer OHP was also employed for the measurement of heat transfer rate and it was effectively work for all the working fluids [8]. To evaluate the characteristics of the working fluids micro OHP was used with trapezoidal channels. Two different start-up behaviours were used such as start-up with and without bubble nucleation. Comparison was made and finally, concluded that start-up with bubble nucleation was the better than that of without bubble nucleation [9]. To measure performance of the start-up mechanism filler ratio, heat input, working fluids are the major concern in evaluation process. Finally, in case of acetone filled OHP had a higher thermal performance compare to the water filled OHP at 60 and $300 \mathrm{~W}[10]$. Whereas in multilayer OHP system, two kinds of novel 3D-OHPs coupled with 2D-OHPs were used by using phase change materials (paraffin wax) for the thermal management. The solidification of paraffin wax with 4 layers OHPs was 0.48 times greater than that of pre paraffin wax with 3 layers [11]. Whereas in case of ferrite ferro-nano-fluids with OHP operation had a high heat transfer and extreme temperature functionality for the applications can be used [12]. In sintered copper-form wicks OHP with an ethanol as a working fluid with $50 \%$ of volumetric filling ratio. These combinations profound improvement in the FPOHP performance and there was a reduction in start-up temperature [13].

A novel method of directive absorptive nano-fluids in the OHP was introduced. It was noticed that an effective capture of solar energy and transport it simultaneously without any external pumping power is required [14]. A novel periodic expansion for condenser was proposed to evaluate the performance of thermo-hydrodynamic with phase change process. The result reveals that the thermal efficiency was increased by $45 \%$ at the expansion condenser [15]. In high-temperature liquid metal oscillating heat pipe with sodium-potassium alloy was used as a working fluid. With a filling ratio of $45 \%$ at different input power, study reviled that at $3169 \mathrm{~W}$ there was a minimum thermal resistance of $0.08^{\circ} \mathrm{C} / \mathrm{W}$ was achieved [16]. OHP-LiCl solution was investigated there was a reduction in thermal resistance of $62 \%$. In case of low filling ratio of $45 \%$ of $\mathrm{LiC}$ solution it reduces the temperature at evaporator section [17]. The flat plate OHP with dual-serpentine-channel was designed and determines the OHP thermal performance. The start-up temperature was increased slowly and it reaches the approximately 41 to $46^{\circ} \mathrm{C}$. The overall thermal conductivity was increased by 5.8 times compare to the existing setup [18]. To reduce the negative effects a multiple heat source was implemented and finally, developed minimum thermal resistance was achieved than compare to the Al6063 Alloy [19]. For all the working fluids the rate of increase in heat transfer was $10 \%$, to evaluate this heat exchanger at the model was developed and model was agreed very well with the experimental data [20]. The thermal performance of OHP with ionic liquids was investigated the heat transfer performance showed a slight decrease of 10\% for 220W [21-25].

According to the about mentioned reports, behaviour of nano-fluids, thermal performance of the novel setup, development of new fluids with OHP was determined. But comparative statements were not been carried out with the existing results. Therefore, optimum combinations of the nano-fluids with OHP need to be evaluated for the better understating of the combined effect of nano-fluids. In 
the present investigations, prediction of acetone for the close loop OHP with a filler ration of 50\% to $80 \%$. Results were drawn based on the observations and finally, predictive equations were developed for the evaluation of performance prediction models.

\section{Methodology}

Experiments was conducted by using a newly fabricated oscillating heat pipe setup consists of copper tubes, glass tube, silicon rubber tube, mica heater, condenser, K-type thermocouple, glass wool, data acquisition system, and heat control unit respectively. Acetone with four turns oscillating heat pipe was used to determine the thermal performance of the OHP system [25-30]. The physical and thermodynamic properties of Acetone (working fluid) is tabulated in Table 1 . To evaluate the thermal performance filler ratio of $50 \%, 60 \%, 70 \%$ and $80 \%$ ) and heat input of $30 \mathrm{~W}, 35 \mathrm{~W}$ and $40 \mathrm{~W}$ were considered as an input to the OHP. The required amount of working fluid is filled through a syringe by opening one end the silicon rubber tube and the rubber tube is closed and ensured for leakage proof. After performing the leakage proof thermocouples display was checked, Mica heater plate was connected to the power controller by adjusting the suitable heat input to maintain the steady state temperature. If once the pulsation of the liquid begins and the reading has been taken until flow reaches steady state. Once the actual reading for a particular heat input is reached, the system is kept for cooling the temperature of the copper pipes and the glass tube is monitored in the system. Once the pulsations of the liquid are stopped the procedure repeats the heater plate is adjusted to the suitable heat input and the readings are tabulated. The overall oscillating heat pipe setup is shown in Figure 1.

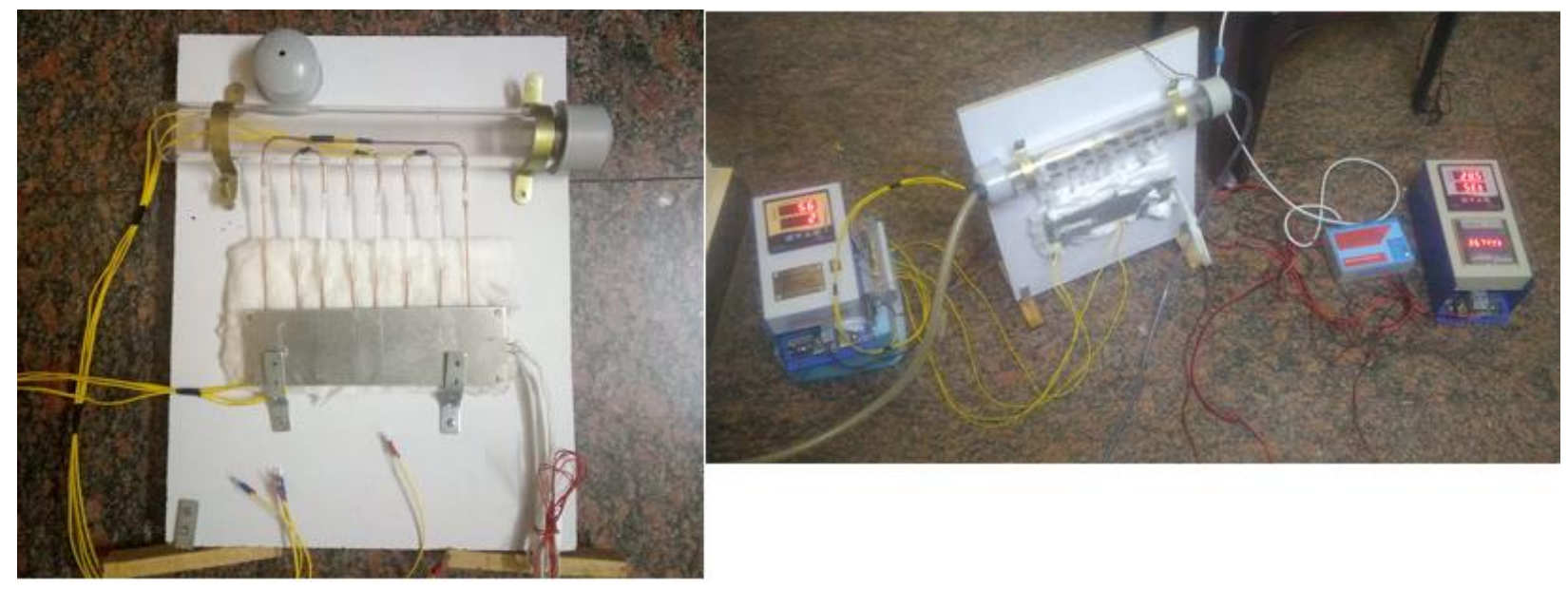

Fig. 1. Experimental setup

Table 1

The physical and thermodynamic properties of Acetone

\begin{tabular}{lllll}
\hline $\begin{array}{l}\text { Working } \\
\text { Fluid }\end{array}$ & Boiling Point $\left({ }^{\circ} \mathrm{C}\right)$ & $\begin{array}{l}\text { Melting Point (Solid } \\
\text { state) }\left({ }^{\circ} \mathrm{C}\right)\end{array}$ & $\begin{array}{l}\text { Useful Temp. Range } \\
\left({ }^{\circ} \mathrm{C}\right)\end{array}$ & $\begin{array}{l}\text { Specific Heat, } \\
\mathrm{Cp}(\mathrm{J} / \mathrm{Kg}-\mathrm{K})\end{array}$ \\
\hline Acetone & 57 & -95 & $0-120$ & 2031 \\
\hline
\end{tabular}




\section{Results and Discussion}

Heat transfer performance of the OHP with acetone was determined by considering filler ratio of $50 \%$ to $80 \%$ and heat input of $15 \mathrm{~W}, 20 \mathrm{~W}, 25 \mathrm{~W}, 30 \mathrm{~W}, 35 \mathrm{~W}$ and $40 \mathrm{~W}$ was considered. The difference in temperature of evaporator and condenser section temperatures with heat input is studied at steady state condition [26-30]. The obtained results indicated that higher fill ratio of working fluid shows the better results in terms of reduction in difference in temperature, increased heat transfer coefficient across the evaporator and condenser. Based on the experimental investigations the change in temperature, heat transfer coefficient and thermal resistance was measured. Finally, experimental result was validated by using statistical analysis. Based on uncertainty analysis, measured and predicted values were explained in details for the better understanding of the developed OHP [31-35].

\subsection{Temperature Variation for Acetone}

For all the filler ratio of $50 \%$ to $80 \%$ by varying the heat input of $15 \mathrm{~W}$ to $40 \mathrm{~W}$ was noted down. Oscillations is depended on the thermal properties of the filled fluid and the heat input. At the heat input of 15W there was no oscillations up to 1850 seconds was observed as shown in Figure 4(a), whereas in case of $20 \mathrm{~W}, 25 \mathrm{~W}, 30 \mathrm{~W}, 35 \mathrm{~W}$ and $40 \mathrm{~W}$ with a filler ration of $50 \%$ was observed at 1650 s, 1250 s, 800 s, 700 s and 550 s respectively. At the filler ratio of $70 \%$ with a heat input of $30 \mathrm{~W}$ and $35 \mathrm{~W}$, there was not much different in temperature was achieved at $800 \mathrm{~s}$. The average increase in temperature for $50 \%, 60 \%, 70 \%$ and $80 \%$ were $7.02^{\circ} \mathrm{C}, 6.38^{\circ} \mathrm{C}, 6.79^{\circ} \mathrm{C}$ and $6.03^{\circ} \mathrm{C}$ respectively. Therefore, there was a minimum temperature different was measured for $80 \%$ filler ratio at $40 \mathrm{~W}$ heat input [32-35]. Similar results were reported elsewhere [36-38]. The variation of temperature with different filler ratio of acetone with increase in heat input for all the combinations is shown in Figure 2(a) to Figure 2(f). Similarly, average temperature difference $\left(T_{e}-T_{c}\right)$ with heat input is shown in Figure 3. 


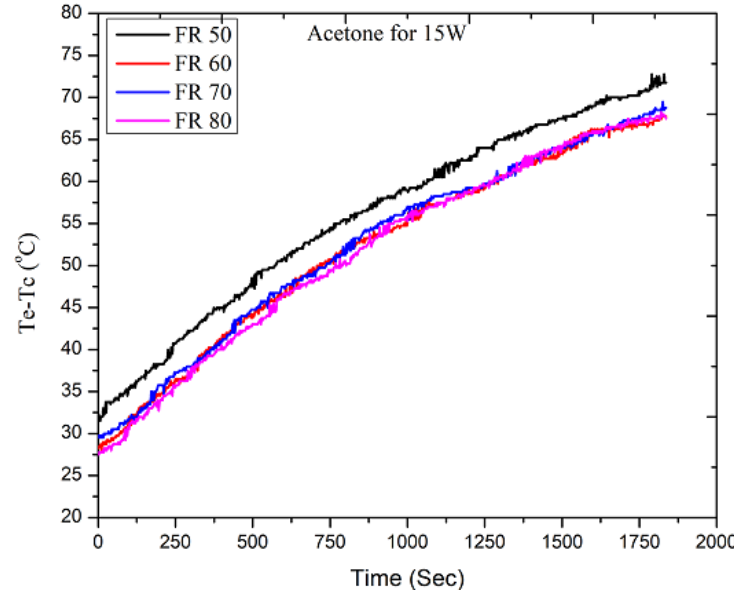

(a)

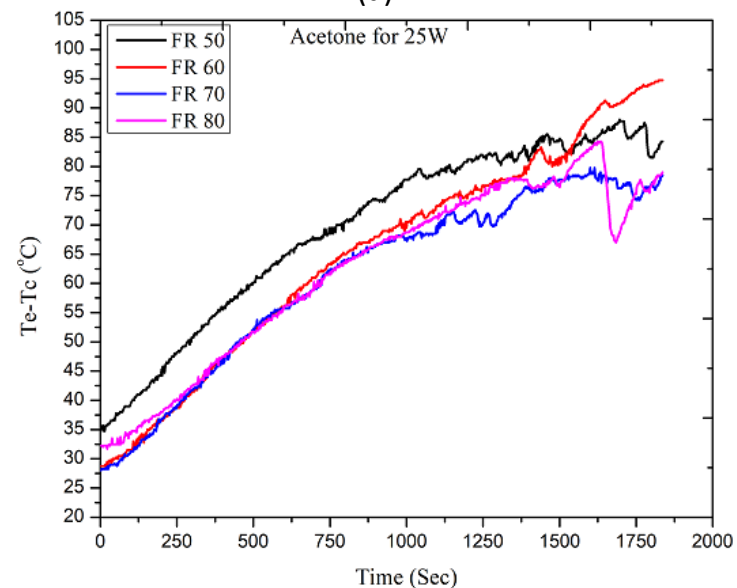

(c)

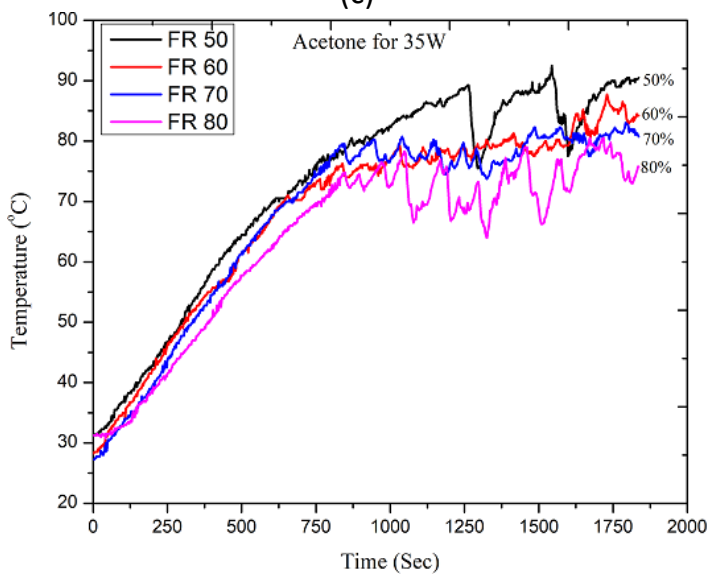

(e)

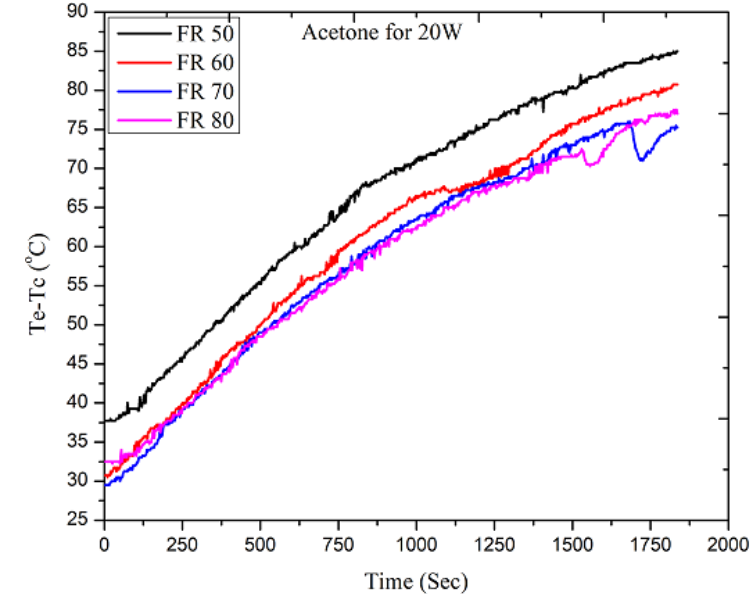

(b)

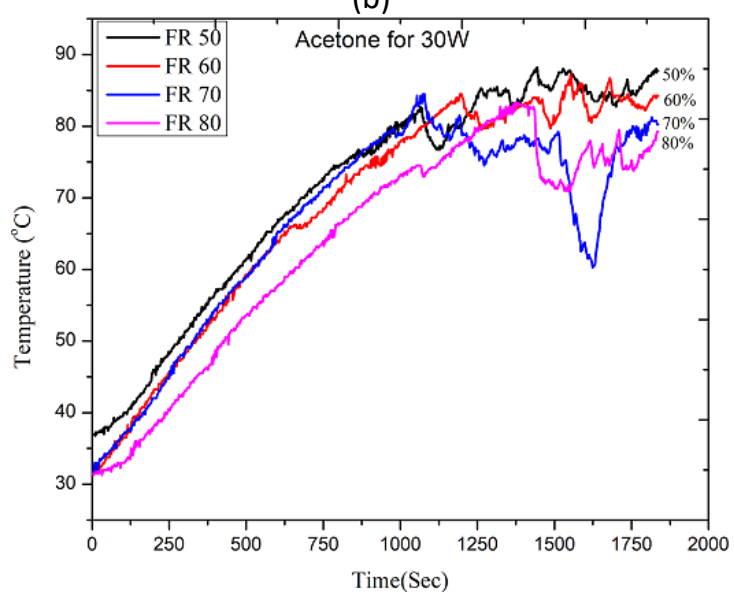

(d)

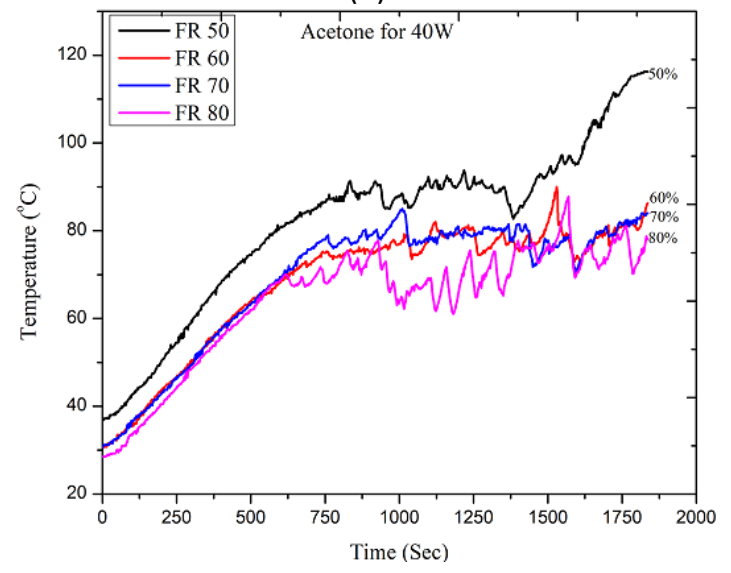

(f)

Fig. 2. Temperature variation for acetone filled at different heat input: (a) $15 \mathrm{~W}$, (b) $20 \mathrm{~W}$, (c) $25 \mathrm{~W}$, (d) $30 \mathrm{~W}$, (e) $35 \mathrm{~W}$ and (f) $40 \mathrm{~W}$ 


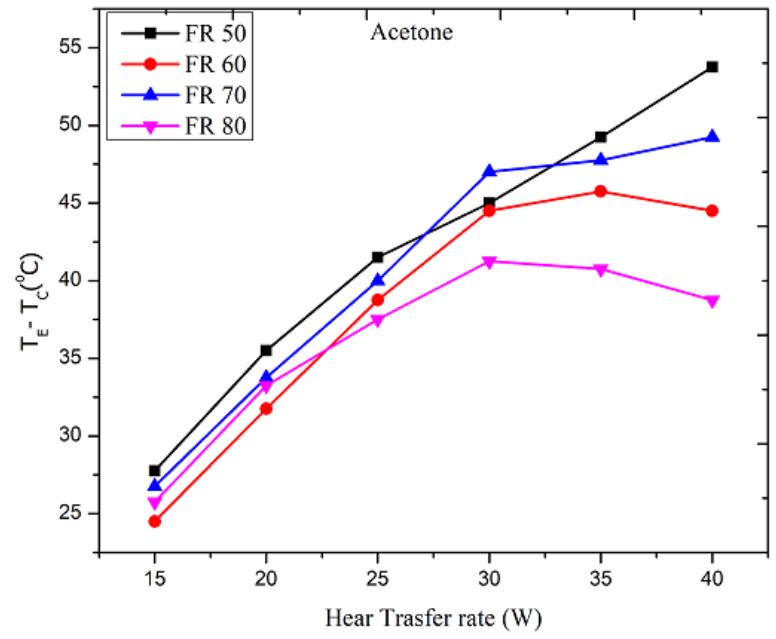

Fig. 3. Average temperature difference $\left(T_{e}-T_{c}\right)$ with heat input for different filler ratio

\subsection{Performance of Heat Transfer Coefficient with Acetone}

Based on the different heat input with filter ratio combinations considered heat transfer rate is determined. Figure 4 illustrates the heat transfer coefficient and heat input for different filler ratio. For the developed OHP system with acetone at 50\% filler ratio the increase in heat transfer coefficient of $37 \%$. Whereas in case of $80 \%$ filler ratio it was $77 \%$ increase in heat transfer coefficient with a heat input of $40 \mathrm{~W}$. Therefore, as the filler ratio increases, there is an increase in heat transfer coefficient because of high convective heat transfer coefficient as the filler ratio increases. Convective heat transfer co-efficient is given by:

$h=\frac{Q}{A(T E-T C)} \frac{W}{m^{2} C}$

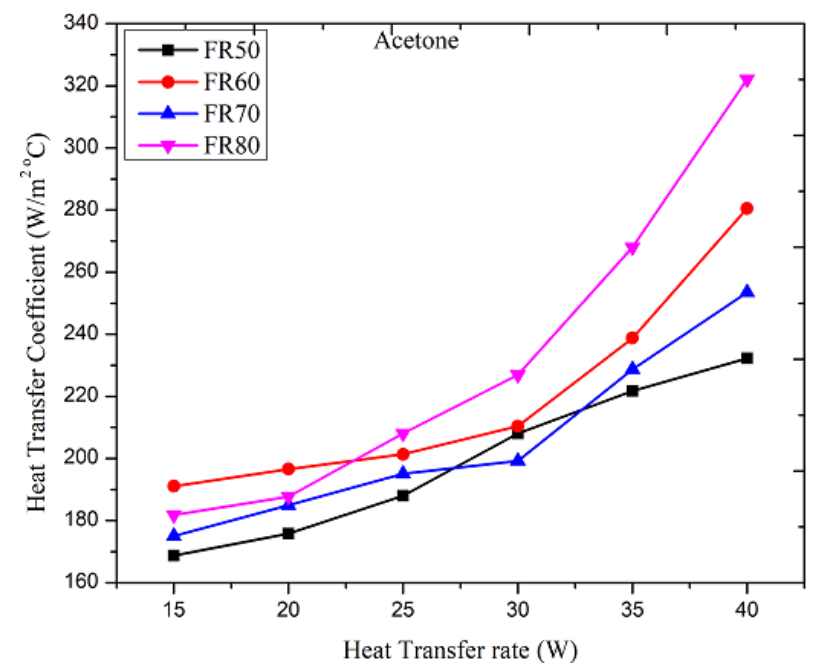

Fig. 4. Average heat transfer coefficient with heat transfer rate for different filler ratio 


\subsection{Performance of Thermal Resistance with Acetone}

Figure 5 illustrate that the thermal resistance and heat input for different filler ratio of OHP is drawn. The experiments were conducted for three times to ensure the accuracy of the new equipment and experimentations. It can be seen that the filler ratio of $80 \%$ there is a decrease thermal resistance by $43 \%$ than compare to $50 \%$ filler ratio with a heat input of $40 \mathrm{~W}$. This is because as the volume increases by $80 \%$ there was a better heat transfer can be achieved come to the $50 \%$. The Thermal Resistance $\mathrm{R}$ is given by:

$R=\frac{T E-T C}{Q}{ }^{\circ} C / W$

Therefore, there is a decrease in thermal resistance with increase in filler ratio for the higher heat input of $40 \mathrm{~W}$ is shown in Figure 5.

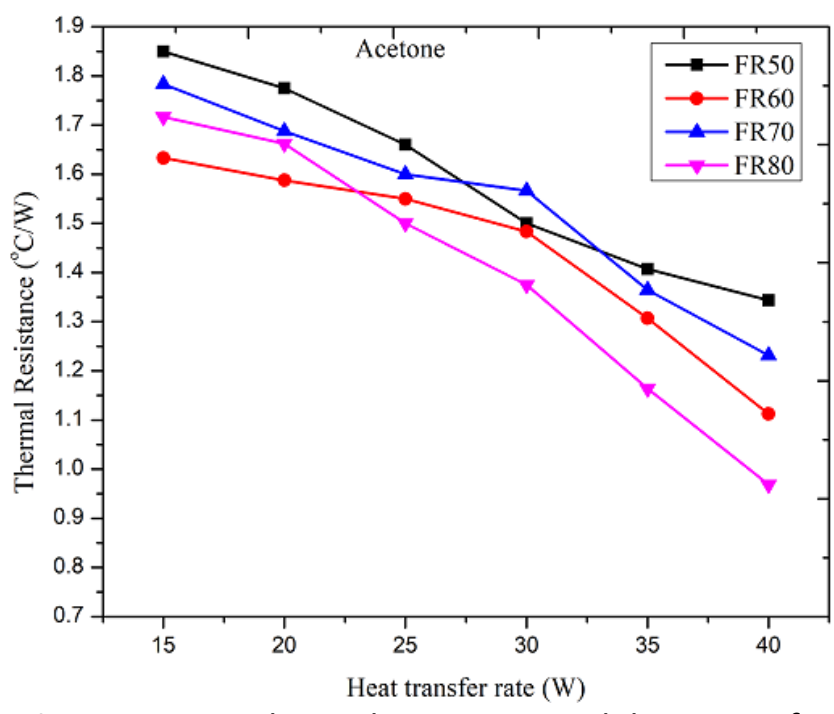

Fig. 5. Average thermal resistance with heat transfer rate for different filler ratio

\subsection{Normal Probability Analysis}

To observe the normality of the experimental data sets, Kolmogorov test was used to perform the probability value. This test is clearly shows that the observed values for Te-Tc, heat transfer coefficient and thermal resistance data sets are normally distributed on $45^{\circ}$ line with a $\mu$ values are $39.34,214.34,1.492$ and $\sigma$ values are $8.12,37.25,0.226$ as represented in the Figure 6, Figure 7 and Figure 8 respectively. Hence the data recorded form the developed setup is reasonably good with acceptable range. 


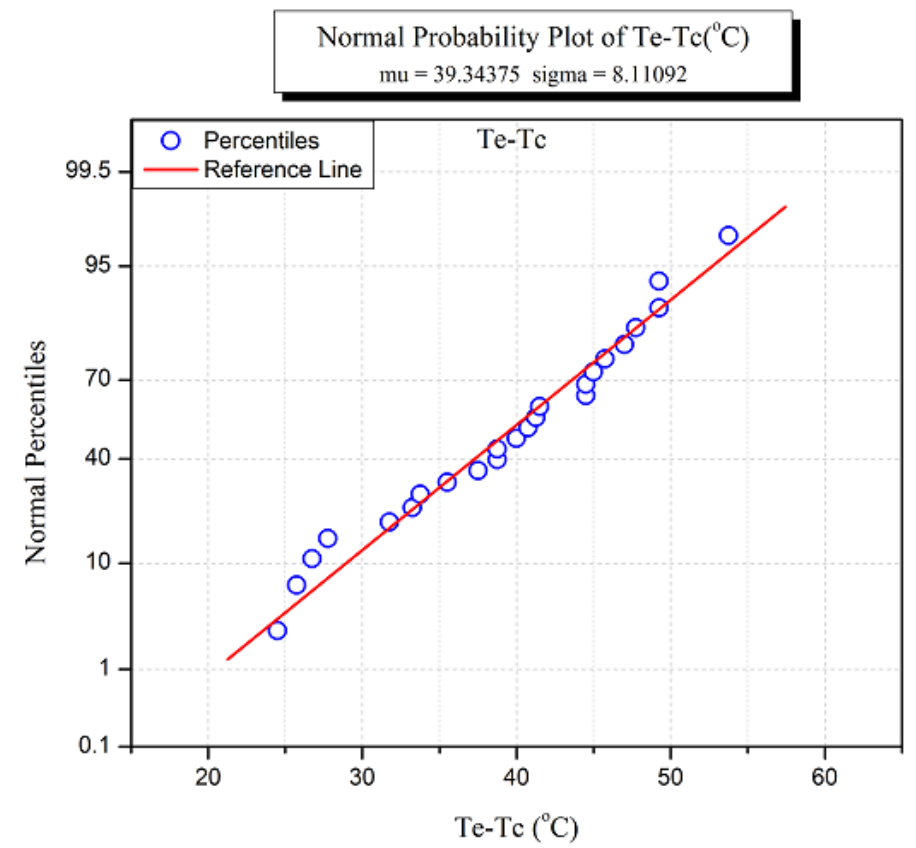

Fig. 6. Normal probability plot for change in temperature of acetone for evaporator and condenser



Fig. 7. Normal probability plot for heat transfer coefficient for acetone 


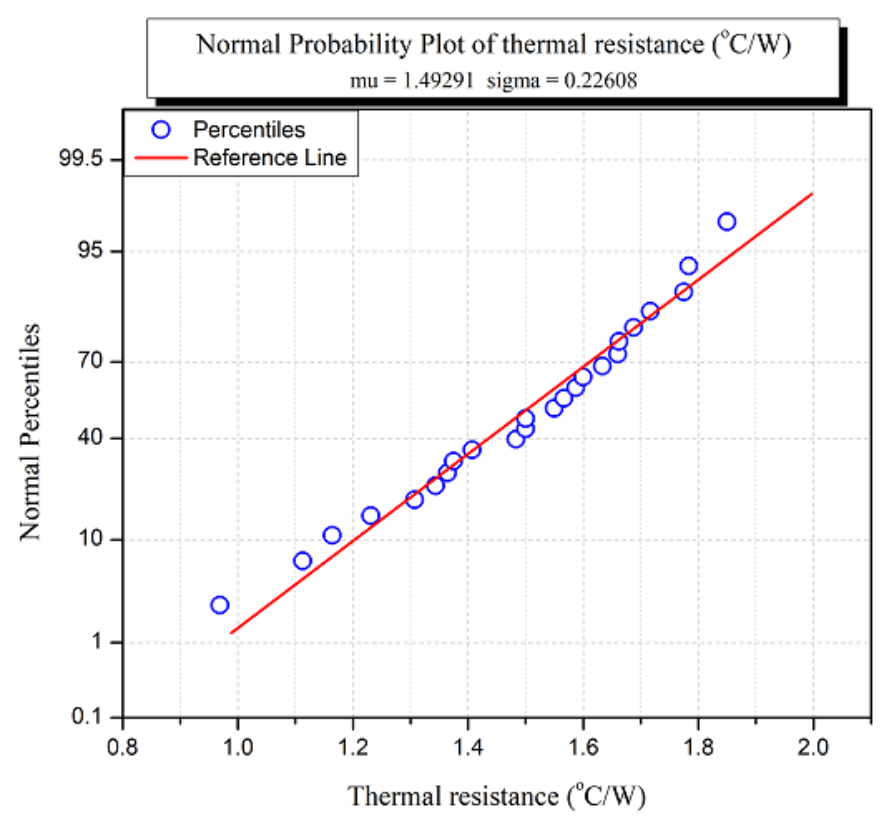

Fig. 8. Normal probability plot for thermal resistance for acetone

\subsection{Statistical Analysis}

Regression and Analysis of variance (ANOVA) method is used to predict the parameters experimentally to find the significant factors are statistically significant. MINITAB was a powerful statistical tool to obtained or analyse the significance of factors [22-25,32-36]. In the present analysis filler ratio and heat input was considered as an input variable to determine temperature difference (Te-Tc), heat transfer coefficient and thermal resistance. Final based on the multiple regression analysis significant parameters was determined. Based on the $F$ test results heat input and combination of heat input and filler ratio was the major significant parameters on heat transfer coefficient and thermal resistance for acetone. For all the combinations considered the predicted equations for Te-Tc, heat transfer coefficient and thermal resistance the coefficient of determinations was $93.68 \%, 89.08 \%$ and $91.24 \%$ respectively and is shown in Eq. (3) to Eq. (5). Therefore, the models are clearly shows that the P-value of the independent variables is $95 \%$ of confidence interval and the details results are shown in Table 2. To measure the degree of fitness the relationship between the predicted and experimental values are shown in Figure 9(a) to Figure 9(c).

Finally, uncertainty analysis is carried out to differential the measured and predicted data. Figure 10(a) to Figure 10(c) clearly shows that the error between the samples was less than $5 \%$ for Te-Tc, heat transfer coefficient and thermal resistance. Therefore, the predicted equations can be utilized for the different combinations of filler ratio and heat input with a confidence interval of $95 \%$.

$$
\begin{aligned}
\text { Te-Tc }= & -29.7+0.449 F R+3.712 \text { heat transfer }-0.00177 F R^{*} F R-0.03656 \text { heat transfer*heat } \\
& \text { transfer }-0.01353 \mathrm{FR}^{*} \text { heat transfer } \quad R^{2}=93.68
\end{aligned}
$$

Heat transfer coefficient $=354-3.20 \mathrm{FR}-9.17$ heat transfer $+0.0143 \mathrm{FR} * \mathrm{FR}$

$$
\begin{aligned}
&+0.1382 \text { heat transfer*heat transfer }+ 0.0802 F R^{*} \text { heat transfer } \\
& R^{2}=89.80
\end{aligned}
$$


Thermal resistance $=1.645+0.0021 \mathrm{FR}+0.0214$ heat transfer $+0.000007 \mathrm{FR} * \mathrm{FR}-0.000482$ heat transfer*heat transfer $-0.000283 \mathrm{FR}^{*}$ heat transfer

$$
R^{2}=91.24
$$

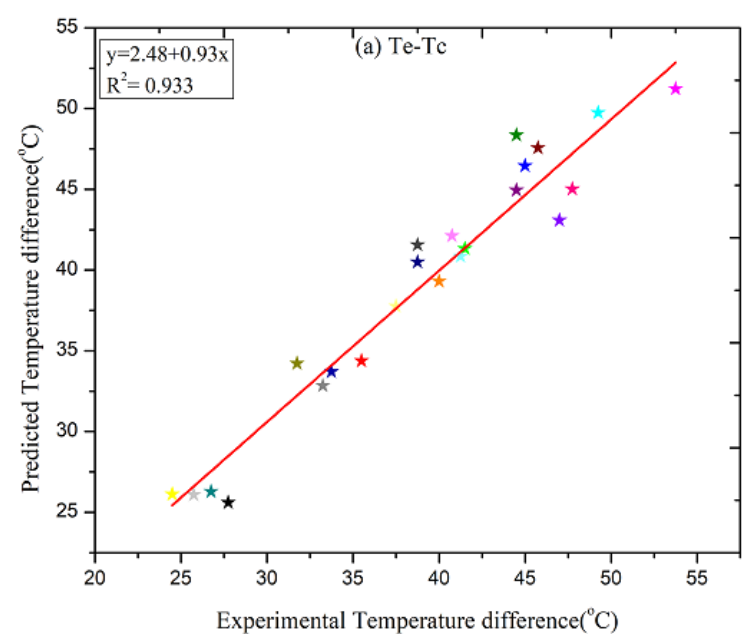

(a)

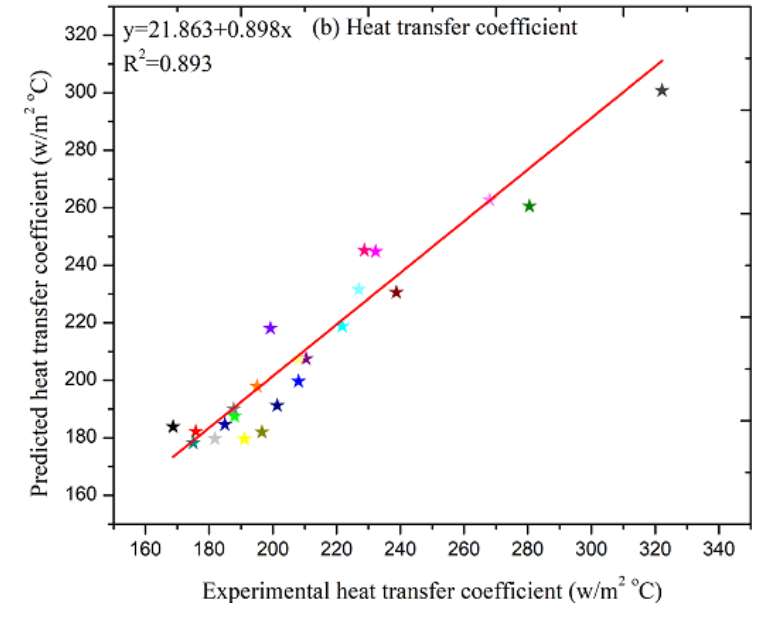

(b)

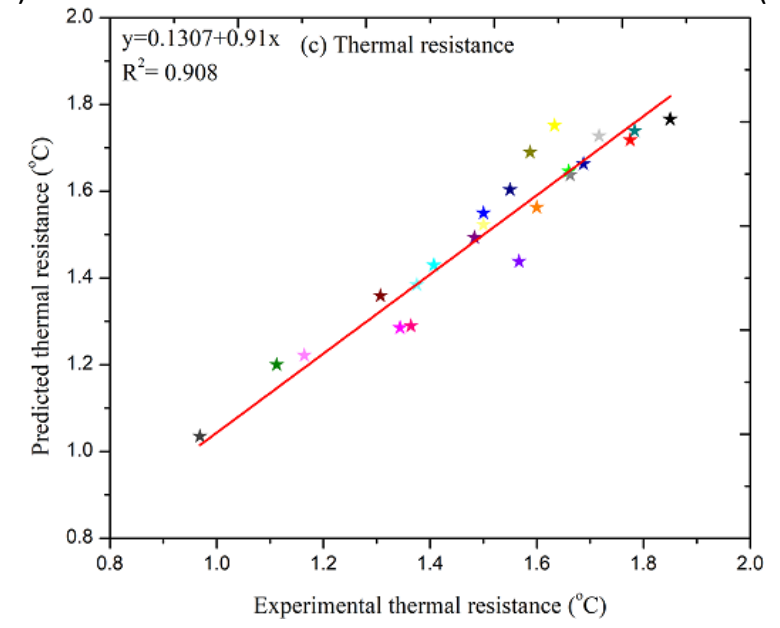

(c)

Fig. 9. Relationship between predicted and experimental values for (a) Te-Tc, (b) heat transfer coefficient and (c) Thermal resistance 


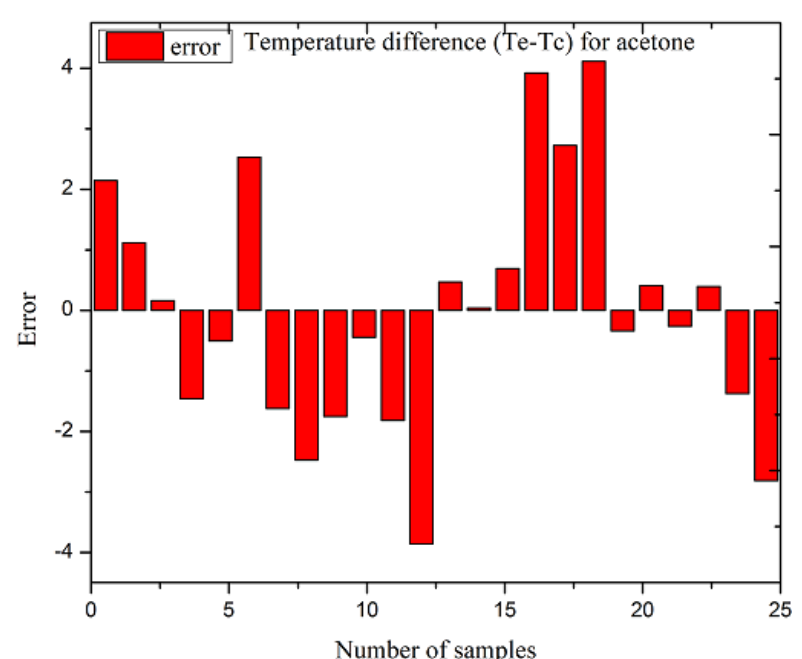

(a)

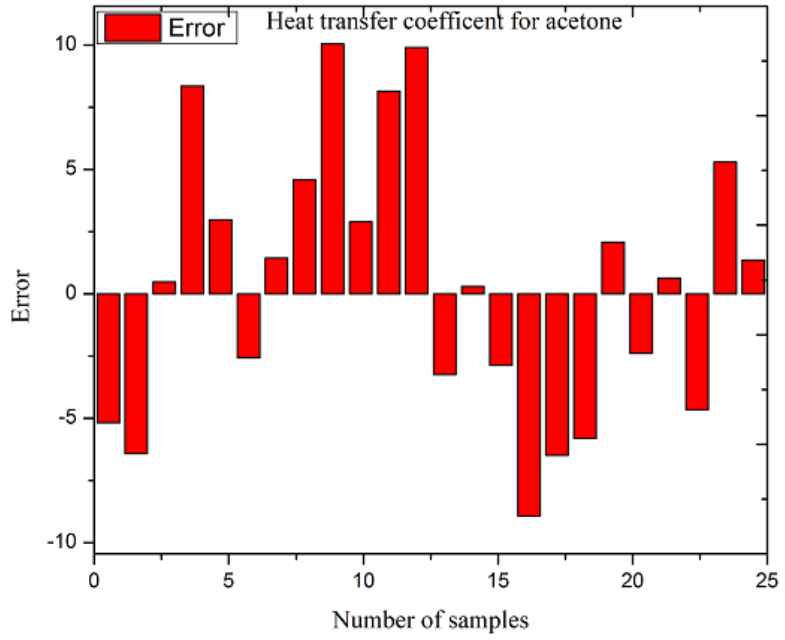

(b)

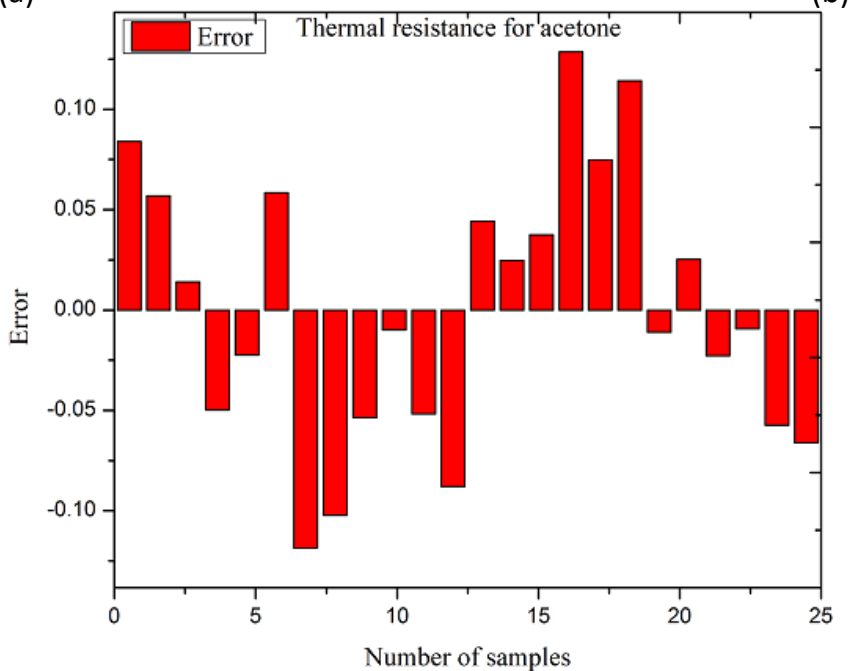

(c)

Fig. 10. Error values for (a) Te-Tc, (b) heat transfer coefficient and (c) Thermal resistance

Table 2

Regression models for significant variables

\begin{tabular}{|c|c|c|c|c|c|c|c|c|c|}
\hline Model & Variable & Coefficient & $\begin{array}{l}\text { Standard } \\
\text { error }\end{array}$ & $\begin{array}{l}\mathrm{t}- \\
\text { value }\end{array}$ & $\begin{array}{l}\text { Tabulated } \\
\text { t-value }\end{array}$ & $\begin{array}{l}\text { F- } \\
\text { value }\end{array}$ & $\begin{array}{l}\text { Tabulated } \\
\text { F- ratio }\end{array}$ & $\mathrm{R}^{2}(\%)$ & $\begin{array}{l}\text { Adjusted } \\
\mathrm{R}^{2}(\%)\end{array}$ \\
\hline \multirow[t]{8}{*}{ Eq. (4) } & \multicolumn{9}{|c|}{ Temperature difference (Te-Tc) } \\
\hline & Constant & -29.7 & 22.0 & -1.35 & 1.71 & 53.40 & 1.97 & 93.68 & 91.93 \\
\hline & Filler Ratio & 0.449 & 0.628 & 0.72 & & 0.51 & & & \\
\hline & $\begin{array}{l}\text { Heat transfer } \\
\text { rate }\end{array}$ & 3.712 & 0.527 & 7.04 & & 49.63 & & & \\
\hline & Filler ratio * & -0.00177 & 0.00470 & -0.38 & & 0.14 & & & \\
\hline & Filler ratio & & & & & & & & \\
\hline & $\begin{array}{l}\text { Heat transfer } \\
\text { rate }{ }^{*} \text { Heat } \\
\text { transfer rate }\end{array}$ & -0.03656 & 0.00754 & -4.85 & & 23.50 & & & \\
\hline & $\begin{array}{l}\text { Filler ratio* } \\
\text { heat transfer }\end{array}$ & -0.01353 & 0.00493 & -2.75 & & 7.54 & & & \\
\hline \multirow[t]{4}{*}{ Eq. (5) } & \multicolumn{9}{|c|}{ Heat Transfer Coefficient } \\
\hline & Constant & 354 & 129 & 2.75 & 1.71 & 31.69 & 1.97 & 89.80 & 86.97 \\
\hline & Filler ratio & -3.20 & 3.66 & -0.87 & & 0.76 & & & \\
\hline & $\begin{array}{l}\text { Heat transfer } \\
\text { rate }\end{array}$ & -9.17 & 3.08 & -2.98 & & 8.89 & & & \\
\hline
\end{tabular}




\begin{tabular}{|c|c|c|c|c|c|c|c|c|c|}
\hline & $\begin{array}{l}\text { Filler ratio } \\
\text { filler ratio }\end{array}$ & 0.0143 & 0.0275 & 0.52 & & 0.27 & & & \\
\hline & $\begin{array}{l}\text { Heat transfer } \\
\text { rate }{ }^{*} \text { Heat } \\
\text { transfer rate }\end{array}$ & 0.1382 & 0.0440 & 3.14 & & 9.86 & & & \\
\hline & $\begin{array}{l}\text { Filler ratio* } \\
\text { heat transfer }\end{array}$ & 0.0802 & 0.0288 & 2.79 & & 7.77 & & & \\
\hline \multirow[t]{7}{*}{ Eq. (6) } & \multicolumn{9}{|c|}{ Thermal Resistance } \\
\hline & Constant & 1.645 & 0.724 & 2.27 & 1.71 & 37.50 & 1.97 & 91.24 & 88.81 \\
\hline & Filler ratio & 0.0021 & 0.0206 & 0.10 & & 0.01 & & & \\
\hline & $\begin{array}{l}\text { Heat transfer } \\
\text { rate }\end{array}$ & 0.0214 & 0.0173 & 1.24 & & 1.53 & & & \\
\hline & $\begin{array}{l}\text { Filler ratio } \\
\text { filler ratio }\end{array}$ & 0.000007 & 0.000154 & 0.04 & & 0.00 & & & \\
\hline & $\begin{array}{l}\text { Heat transfer } \\
\text { rate } * \text { Heat } \\
\text { transfer rate }\end{array}$ & -0.000482 & 0.000248 & -1.95 & & 3.79 & & & \\
\hline & $\begin{array}{l}\text { Filler ratio* } \\
\text { heat transfer }\end{array}$ & -0.000283 & 0.000162 & -1.75 & & 3.05 & & & \\
\hline
\end{tabular}

\section{Conclusions}

In this study, experimental investigations of a newly fabricated four turned OHP system were developed to determine the effect acetone as a working fluid on the thermal performance of an OHP. Based on the different heat input and filler ratio the conclusions were drawn as follows

i. Based on the above results the heat input of $40 \mathrm{~W}$ with a filler ratio of $80 \%$ the change in temperature was minimum of $6.03 \%$ than compare to the $50 \%$ of filler ratio of $7.20 \%$. Because of acetone filled OHP had a high oscillating amplitude capacity compare to the water filled OHP.

ii. For newly developed setup, heat transfer coefficient was $37 \%$ for $50 \%$ filler ratio with $40 \mathrm{~W}$ heat input and suddenly increased by $77 \%$ for $80 \%$ filler ratio with a heat input of $40 \mathrm{~W}$ was achieved with acetone filled OHP.

iii. The thermal resistance was decreased by $43 \%$ with a filler ratio of $80 \%$ of acetone than compare to the $50 \%$ of filler ratio with $40 \mathrm{~W}$ heat input was achieved. Therefore, increase in acetone as a filler ratio there was an increase in heat transfer coefficient and decrease in thermal resistance with a minimum temperature difference between the evaporator and condenser can be achieved.

iv. Finally, statistical analysis was used to validate the data extracted from the experimental results. The independent variables are statistically significant for with a P-value of 0.05 . The coefficient of determination for Te-Tc, heat transfer coefficient and thermal resistance is $0.936,0.898$ and 0.912 respectively.

\section{Acknowledgement}

This research was not funded by any grant. 


\section{References}

[1] Qu, Jian, Fengbo Guan, Yaojie Lv, and Yalin Wang. "Experimental study on the heat transport capability of microgrooved oscillating heat pipe." Case Studies in Thermal Engineering 26 (2021): 101210. https://doi.org/10.1016/j.csite.2021.101210

[2] Yin, D., H. Rajab, and H. B. Ma. "Theoretical analysis of maximum filling ratio in an oscillating heat pipe." International Journal of Heat and Mass Transfer $74 \quad$ (2014): $353-357$. https://doi.org/10.1016/j.ijheatmasstransfer.2014.03.018

[3] Xian, Haizhen, Wenjin Xu, Yuning Zhang, Xiaoze Du, and Yongping Yang. "Thermal characteristics and flow patterns of oscillating heat pipe with pulse heating." International Journal of Heat and Mass Transfer 79 (2014): $332-341$. https://doi.org/10.1016/i.ijheatmasstransfer.2014.08.002

[4] Yin, D., H. Wang, H. B. Ma, and Y. L. Ji. "Operation limitation of an oscillating heat pipe." International Journal of Heat and Mass Transfer 94 (2016): 366-372. https://doi.org/10.1016/j.ijheatmasstransfer.2015.11.039

[5] Su, Xinjun, Ming Zhang, Wei Han, and Xianmin Guo. "Experimental study on the heat transfer performance of an oscillating heat pipe with self-rewetting nanofluid." International Journal of Heat and Mass Transfer 100 (2016): 378-385. https://doi.org/10.1016/i.ijheatmasstransfer.2016.04.094

[6] Qu, Jian, Xiaojun Li, Yingying Cui, and Qian Wang. "Design and experimental study on a hybrid flexible oscillating heat pipe." International Journal of Heat and Mass Transfer 107 (2017): 640-645. https://doi.org/10.1016/j.ijheatmasstransfer.2016.11.076

[7] Zhao, Jiateng, Jie Qu, and Zhonghao Rao. "Experiment investigation on thermal performance of a large-scale oscillating heat pipe with self-rewetting fluid used for thermal energy storage." International Journal of Heat and Mass Transfer 108 (2017): 760-769. https://doi.org/10.1016/j.ijheatmasstransfer.2016.12.093

[8] Ibrahim, Omar T., J. Gabriel Monroe, Scott M. Thompson, Nima Shamsaei, Hassina Bilheux, Alaa Elwany, and Linkan Bian. "An investigation of a multi-layered oscillating heat pipe additively manufactured from Ti-6Al-4V powder." International Journal of Heat and Mass Transfer 108 (2017): $1036-1047$. https://doi.org/10.1016/j.ijheatmasstransfer.2016.12.063

[9] Sun, Qin, Jian Qu, Jianping Yuan, and Hai Wang. "Start-up characteristics of MEMS-based micro oscillating heat pipe with and without bubble nucleation." International Journal of Heat and Mass Transfer 122 (2018): 515-528. https://doi.org/10.1016/i.ijheatmasstransfer.2018.02.003

[10] Hao, Tingting, Hongbin Ma, and Xuehu Ma. "Heat transfer performance of polytetrafluoroethylene oscillating heat pipe with water, ethanol, and acetone as working fluids." International Journal of Heat and Mass Transfer 131 (2019): 109-120. https://doi.org/10.1016/j.ijheatmasstransfer.2018.08.133

[11] Qu, Jie, Zhiqi Ke, Anhao Zuo, and Zhonghao Rao. "Experimental investigation on thermal performance of phase change material coupled with three-dimensional oscillating heat pipe (PCM/3DOHP) for thermal management application." International Journal of Heat and Mass Transfer 129 (2019): 773-782. https://doi.org/10.1016/i.ijheatmasstransfer.2018.10.019

[12] Monroe, J. Gabriel, Swati Kumari, John D. Fairley, Keisha B. Walters, Matthew J. Berg, and Scott M. Thompson. "On the energy harvesting and heat transfer ability of a ferro-nanofluid oscillating heat pipe." International Journal of Heat and Mass Transfer 132 (2019): 162-171. https://doi.org/10.1016/i.ijheatmasstransfer.2018.11.096

[13] Qu, Jian, Qin Sun, Hai Wang, Donghui Zhang, and Jianping Yuan. "Performance characteristics of flat-plate oscillating heat pipe with porous metal-foam wicks." International Journal of Heat and Mass Transfer 137 (2019): 20-30. https://doi.org/10.1016/i.ijheatmasstransfer.2019.03.107

[14] Jin, Haichuan, Guiping Lin, Aimen Zeiny, Lizhan Bai, Jinjing Cai, and Dongsheng Wen. "Experimental study of transparent oscillating heat pipes filled with solar absorptive nanofluids." International Journal of Heat and Mass Transfer 139 (2019): 789-801. https://doi.org/10.1016/j.ijheatmasstransfer.2019.04.117

[15] Wang, Wei-Wei, Lei Wang, Yang Cai, Guo-Biao Yang, Fu-Yun Zhao, Di Liu, and Qing-Hua Yu. "Thermo-hydrodynamic model and parametric optimization of a novel miniature closed oscillating heat pipe with periodic expansionconstriction condensers." International Journal of Heat and Mass Transfer 152 (2020): 119460. https://doi.org/10.1016/j.ijheatmasstransfer.2020.119460

[16] Ji, Yulong, Mengke Wu, Yanmin Feng, Chunrong Yu, Lilin Chu, Chao Chang, Yantao Li, Xiu Xiao, and Hongbin Ma. "An experimental investigation on the heat transfer performance of a liquid metal high-temperature oscillating heat pipe." International Journal of Heat and Mass Transfer 149 (2020): 119198. https://doi.org/10.1016/i.ijheatmasstransfer.2019.119198

[17] Wang, Peng, Xiaoyu Cui, Jianhua Weng, Ziqiu Cai, and Ren Cai. "Experimental investigation of the heat transfer performance of an oscillating heat pipe with $\mathrm{LiCl}$ salt solution." International Journal of Heat and Mass Transfer 158 (2020): 120033. https://doi.org/10.1016/j.ijheatmasstransfer.2020.120033 
[18] Liu, Xiangdong, Xi Chen, Ziwen Zhang, and Yongping Chen. "Thermal performance of a novel dual-serpentinechannel flat-plate oscillating heat pipe used for multiple heat sources and sinks." International Journal of Heat and Mass Transfer 161 (2020): 120293. https://doi.org/10.1016/j.ijheatmasstransfer.2020.120293

[19] Chen, Xi, Shengkai Chen, Ziwen Zhang, Dongke Sun, and Xiangdong Liu. "Heat transfer investigation of a flat-plate oscillating heat pipe with tandem dual channels under nonuniform heating." International Journal of Heat and Mass Transfer 180 (2021): 121830. https://doi.org/10.1016/j.ijheatmasstransfer.2021.121830

[20] Nuntaphan, Atipoang, Sanparwat Vithayasai, Nat Vorayos, Nattanee Vorayos, and Tanongkiat Kiatsiriroat. "Use of oscillating heat pipe technique as extended surface in wire-on-tube heat exchanger for heat transfer enhancement." International Communications in Heat and Mass Transfer 37, no. 3 (2010): $287-292$. https://doi.org/10.1016/i.icheatmasstransfer.2009.11.006

[21] Liang, Qianqing, Tingting Hao, Kai Wang, Xuehu Ma, Zhong Lan, and Yaxiong Wang. "Startup and transport characteristics of oscillating heat pipe using ionic liquids." International Communications in Heat and Mass Transfer 94 (2018): 1-13. https://doi.org/10.1016/j.icheatmasstransfer.2018.03.004

[22] Shankar, Vijay K., Bijay M. Kunar, and Chivukula S. Murthy. "Experimental investigation and statistical analysis of operational parameters on temperature rise in rock drilling." International Journal of Heat and Technology 36, no. 4 (2018): 1174-1180. https://doi.org/10.18280/ijht.360403

[23] Shankar, Vijay Kumar, B. M. Kunar, and Ch SN Murthy. "ANN model for prediction of bit-rock interface temperature during rotary drilling of limestone using embedded thermocouple technique." Journal of Thermal Analysis and Calorimetry 139, no. 3 (2020): 2273-2282. https://doi.org/10.1007/s10973-019-08646-2

[24] Kumar, S. Vijay, Ch SN Murthy, and B. M. Kunar. "Effect of thermal response on physical properties during drilling operations-A case study." Materials Today: Proceedings 5, no. 2 (2018): 7404-7409. https://doi.org/10.1016/i.matpr.2017.11.411

[25] Krishna, Varna, Vijay K. Shankar, Lakshmidevamma Madarakallu Muniyappa, and Mahagundappa M. Benal. "Prediction of Temperature During Machinability of $\mathrm{Al}_{2} \mathrm{O}_{3}$ Reinforced Al7075." Revue des Composites et des Matériaux Avancés 30, no. 5-6 (2020): 241-246. https://doi.org/10.18280/rcma.305-607

[26] Shen, Chao, Yizhe Zhang, Zhuxuan Wang, Dongwei Zhang, and Zhiying Liu. "Experimental investigation on the heat transfer performance of a flat parallel flow heat pipe." International Journal of Heat and Mass Transfer 168 (2021): 120856. https://doi.org/10.1016/i.ijheatmasstransfer.2020.120856

[27] Xu, Rongji, Chao Zhang, Hao Chen, Qingping Wu, and Ruixiang Wang. "Heat transfer performance of pulsating heat pipe with zeotropic immiscible binary mixtures." International Journal of Heat and Mass Transfer 137 (2019): 31 41. https://doi.org/10.1016/j.ijheatmasstransfer.2019.03.070

[28] Zhang, Dongwei, Zhuantao He, Jian Guan, Songzhen Tang, and Chao Shen. "Heat transfer and flow visualization of pulsating heat pipe with silica nanofluid: An experimental study." International Journal of Heat and Mass Transfer 183 (2022): 122100. https://doi.org/10.1016/j.ijheatmasstransfer.2021.122100

[29] Ewis, Karem Mahmoud. "Effects of Variable Thermal Conductivity and Grashof Number on Non-Darcian Natural Convection Flow of Viscoelastic Fluids with Non Linear Radiation and Dissipations." Journal of Advanced Research in Applied Sciences and Engineering Technology 22, no. 1 (2021): 69-80. https://doi.org/10.37934/araset.22.1.6980

[30] Khan, Ansab Azam, Khairy Zaimi, Suliadi Firdaus Sufahani, and Mohammad Ferdows. "MHD Flow and Heat Transfer of Double Stratified Micropolar Fluid over a Vertical Permeable Shrinking/Stretching Sheet with Chemical Reaction and Heat Source." Journal of Advanced Research in Applied Sciences and Engineering Technology 21, no. 1 (2020): 1-14. https://doi.org/10.37934/araset.21.1.114

[31] Ghiasi, Pedram, Amar Salehi, Seyed Salar Hoseini, Gholamhassan Najafi, Rizalman Mamat, Balkhaya Balkhaya, and Fitri Khoerunnisa. "Investigation of the Effect of Flow Rate on Fluid Heat Transfer in Counter-Flow Helical Heat Exchanger Using CFD Method." CFD Letters 12, no. 3 (2020): 98-111. https://doi.org/10.37934/cfdl.12.3.98111

[32] Zufar, Muhammad, Prem Gunnasegaran, Khai Ching Ng, and Hemantkumar B. Mehta. "Evaluation of the thermal performance of hybrid nanofluids in pulsating heat pipe." CFD Letters 11, no. 11 (2019): 13-24.

[33] Usman, Auwalu Hamisu, Sadiya Ali Rano, Usa Wannasingha Humphries, and Poom Kumam. "Activity of Viscoelastic Nanofluid Film Sprayed on a Stretching Cylinder with Arrhenius Activation Energy and Entropy Generation." Journal of Advanced Research in Micro and Nano Engineering 3, no. 1 (2020): 12-24.

[34] Sofia, Evi, Nandy Putra, and B. Ali Gunawan. "Evaluation of Indirect Evaporative Cooling Performance Integrated with Finned Heat Pipe and Luffa Cylindrica Fiber as Cooling/Wet Media." Journal of Advanced Research in Experimental Fluid Mechanics and Heat Transfer 3, no. 1 (2021): 16-25.

[35] Akbar, Ronald, J. T. Oh, and A. S. Pamitran. "Two-Phase Flow Boiling Heat Transfer Coefficient with R290 in Horizontal $3 \mathrm{~mm}$ Diameter Mini Channel." Journal of Advanced Research in Experimental Fluid Mechanics and Heat Transfer 3, no. 1 (2021): 1-8. 
[36] Zhang, Dongwei, Zhuantao He, Jian Guan, Songzhen Tang, and Chao Shen. "Heat transfer and flow visualization of pulsating heat pipe with silica nanofluid: An experimental study." International Journal of Heat and Mass Transfer 183 (2022): 122100. https://doi.org/10.1016/j.ijheatmasstransfer.2021.122100

[37] Xu, Rongji, Chao Zhang, Hao Chen, Qingping Wu, and Ruixiang Wang. "Heat transfer performance of pulsating heat pipe with zeotropic immiscible binary mixtures." International Journal of Heat and Mass Transfer 137 (2019): $31-$ 41. https://doi.org/10.1016/j.ijheatmasstransfer.2019.03.070

[38] Shen, Chao, Yizhe Zhang, Zhuxuan Wang, Dongwei Zhang, and Zhiying Liu. "Experimental investigation on the heat transfer performance of a flat parallel flow heat pipe." International Journal of Heat and Mass Transfer 168 (2021): 120856. https://doi.org/10.1016/i.ijheatmasstransfer.2020.120856 